\title{
Evaluation of Resistance at Supporting Pulley of Messenger Wire and Its Influence on Current Collection Characteristics
}

\author{
Satoru AMARI \\ Researcher, \\ Mizuki TSUNEMOTO \\ Researcher, \\ Contact Line Structures Laboratory, Power Supply Technology Division \\ Shunichi KUSUMI \\ JR Soken Electric Consulting \\ (Formerly Contact Line Structures Laboratory)
}

Takuya KURAOKA
Takahiro HAMADA

East Japan Railway Company

\section{Michihito MINAMOTO}

Tension in overhead contact line systems needs to be constant to maintain acceptable levels of current collection. However, it is conceivable that the tension is not exactly constant, because of the resistance at the supporting pulley of messenger wire. In this study, we investigated the mechanism of such resistance, carried out measurement of tension fluctuation, and examined the movement of messenger wires as part the investigation. Furthermore, in order to investigate the influence of the resistance at the supporting pulley on the current collection, we carried out a simulation to ascertain how current collection characteristics are influenced by changes in messenger wire tension.

Keywords: supporting pulley of messenger wire, tension, resistance at supporting pulley of messenger wire, current collection

\section{Introduction}

Tension in overhead contact line systems needs to be constant to maintain acceptable levels of current collection. However, since overhead contact line expands and contracts according to a temperature change, its tension is sharply changed between each of a point of fixed terminations of the overhead contact line. Hence, to keep tension constant within a drum (drum: maintenance division of overhead contact lines), each fixed termination is generally equipped with an automatic tension balancer, and the supporting point of messenger wire has a linemovable structure such as a hinged cantilever or pulley. However, it is conceivable that the tension of each span may be different within the same drum because of resistance that restrains the tension and movement of the wire, such as frictional force at a supporting point.

In this study, we investigated the mechanism of the resistance and confirmed it by measuring tension fluctuations and movement in the messenger wire. Furthermore, in order to investigate the influence of the resistance at the supporting pulley on the current collection, we carried out a simulation to ascertain how current collection characteristics are influenced by the change of the tension of the messenger wire.

\section{Resistance at supporting pulley of feeder messenger system}

Recently, overhead contact line systems in the metropolitan areas have been changed from the conventional simple catenary system to the feeder messenger system.
The system of called "integrated overhead catenary system" on JR conventional lines consists of PH356mm2 feeder messenger wire (two wires with a standard tension of $19.6 \mathrm{kN} /$ wire) and GT-Sn-170 contact wires (with a standard tension of $14.7 \mathrm{kN}$ ). Generally, messenger wires are supported by pulley at supporting points, and both terminations are equipped with a STB (spring-type automatic tension balancer).

Supporting pulley of messenger wires have a structure that supports the messenger wire by two pulleys as shown in Fig. 1. In the case of a 50-m span of messenger wire, the load of approximately $1 \mathrm{kN}$ acts on each pulley. The material of the main part of the pulley is polycarbonate, its bush is molybdenum nylon, and its axis is stainless steel. The force that rotates the pulley acts on its upper surface. This force is generated when a difference in tension arises between adjacent spans due to expansion and contraction caused by temperature changes. If the moment caused by this tension difference exceeds the moment caused by the static friction force between shaft and bush, the pulley will begin to rotate.

When tension difference $\Delta T$ acts on the pulley's upper surface as shown in Fig. 2, a condition in which the

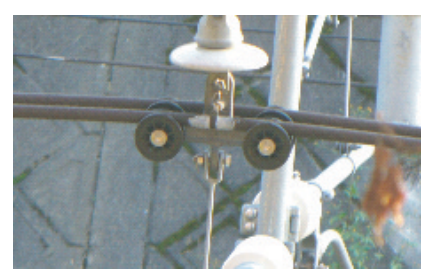

(a) For a straight line

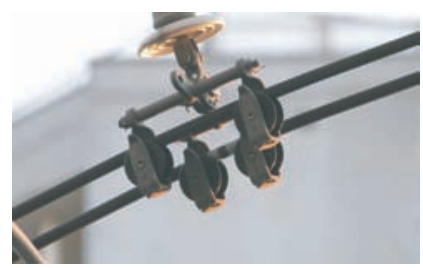

(b) For a curved line
Fig. 1 Messenger wire supporting pulleys 


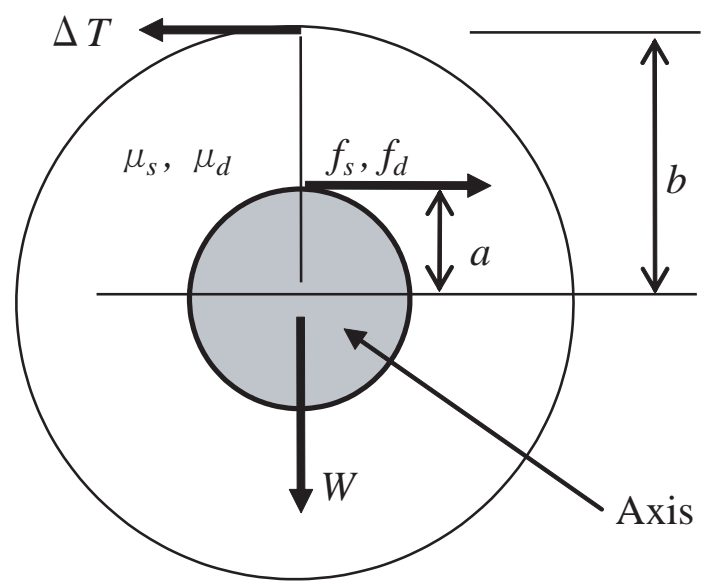

Fig. 2 Forces acting on a pulley

pulley begins to rotate is formulated as shown in (1) to maintain equilibrium of moment.

$$
b \Delta T>a f_{S}=a \mu_{S} W
$$

where $f_{s}=$ static frictional force, $\mu_{s}=$ static frictional coefficient, $W=$ load added to pulley, $a=$ pulley bore radius, and $b=$ radius of pulley measured from the center of rotation.

Equation (1) can be rewritten as follows:

$$
\frac{\Delta T}{W}>\frac{a}{b} \mu_{S}
$$

Generally, the friction coefficient can be calculated as the quotient of the horizontal external force divided by the vertical load of the object. On the other hand, the quotient of the external force acting on the upper surface of a pulley divided by the load added to the pulley will give another coefficient in consideration of the moment of the load about its axis. In this report, $\frac{\Delta T}{W}$ is referred to as the rolling resistance coefficient. If this value becomes small, the pulley will rotate by small force $\Delta T$. As it begins to rotate, the messenger wire will move, the tension will change, and $\Delta T$ will become gradually smaller. When the moment from this $\Delta T$ value becomes smaller than the moment from the dynamic friction force on the axial surface, rotation will stop. Let $f_{d}$ and $\mu_{d}$ be the dynamic friction force and the dynamic friction coefficient respectively, then tension difference $\Delta T$ when rotation stops will satisfy the following equation, similarly to (1).

$$
b \Delta T<a f_{d}=a \mu_{d} W
$$

Tension difference $\Delta T$ that acts on the pulley is given as follows (4):

$$
\Delta T<\frac{a}{b} \mu_{d} W
$$

Even after the pulley rotates, tension difference $\Delta T$ between each side of the pulley remains. Thus, there are two kinds of tension difference: one rotates the pulley, and the other remains after the pulley stops. These tension differences are defined as the resistance at the supporting pulley.

\section{Basic test on restraining tension at supporting points}

In order to investigate the relationship between thermal tension fluctuation and horizontal movement of messenger wires, we performed a basic experiment using test equipment of the feeder messenger type.

\subsection{Measurement method}

Figure 3 shows a schematic outline of the test equipment and sensor placement. Feeder messenger supporting pulleys for straight lines are installed at support points (2) - (5), and those for curved lines are installed at supporting points (1) and (6). The tension of each span is measured using a tension meter installed on the messenger wire, and the horizontal movement of the messenger wire caused by pulley rotation is measured using a displacement gauge installed in each span. Since the messenger wire may move when an insulator inclines even without pulley rotation, displacement gauges to measure the relative horizontal movement of the messenger wire from the supporting structure were also installed at supporting points (1) and (2). Moreover, measurement was also performed in a state with an insulator fixed to the supporting point so that it would not incline.

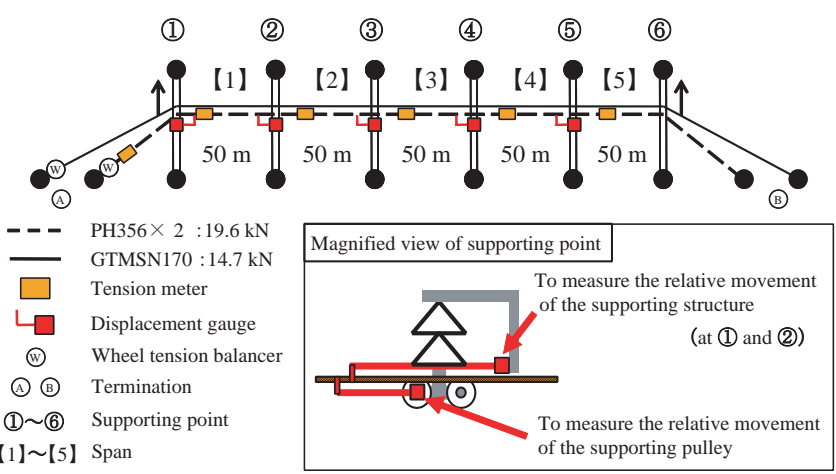

Fig. 3 Schematic outline of the test equipment and sensor placement

\subsection{Result of basic test}

The following points were confirmed from the measurement results:

- The tension of each span in the range from termination (A) to span 【5】 changed approximately by $1.2-2.5 \mathrm{kN}$ according to temperature changes with a range of approximately $14^{\circ} \mathrm{C}$ a day. The farther the span was from the WTB (wheel tension balancer), the larger the amount of change was. Therefore, it is assumable that tension adjustment is not performed smoothly due to resistance at the supporting point.

- Although horizontal movement of the messenger wire stems from pulley rotation did not follow small change of temperature, this movement changed sharply approximately twice a day. Hence, it is confirmed that the pulley does not rotate unless the tension difference according to temperature changes becomes large to some extent. In cases where the measurement position is far from the 
WTB, horizontal movement of the messenger wire stemming from pulley rotation is small, and movement at supporting point (5) is sometimes not seen even once a day.

- The relative horizontal movement of the messenger wire to the supporting structure was changing with the temperature changes, and it was $5.3 \mathrm{~mm}$ per $1^{\circ} \mathrm{C}$ at supporting point (2). This is equivalent to the amount of linear expansion in a messenger wire of approximately $310 \mathrm{~m}$, and it is almost in agreement with the distance of approximately 300 $m$ from supporting point (2) to termination (B). Consequently, it can be presumed that messenger wire movement according to small changes in temperature is generated not by pulley rotation but by the inclination of the insulator.

- When pulley is rotated, relative horizontal movement of the supporting pulley is sharply changed, but relative horizontal movement of the supporting structure is only $20-30 \%$ of this value. Hence, pulley rotation is caused mainly by the movement of the insulator returning to a neutral position, rather than by the movement of the messenger wire.

- The difference in the tension of the span on each side of the supporting pulley gradually increased with temperature changes and decreased rapidly with pulley rotation. This tension difference is approximately $0.3 \mathrm{kN}$ at the time of pulley rotation. Therefore, it is conceivable be thought that the pulley rotates when the tension difference cannot be absorbed by insulator inclination.

- Compared with a case where the supporting pulley is fixed so that the insulator cannot incline, the following results are obtained: the tension difference was smaller by approximately $0.1 \mathrm{kN}$ during pulley rotation, and it was smaller by approximately $0.3 \mathrm{kN}$ after pulley rotation. This can be attributed to the force to restore the inclined insulator to a neutral position being added to the tension difference.

\section{Measurement of resistance at supporting pulleys of messenger wire}

In order to investigate resistance at supporting pulleys of messenger wire and to study countermeasures to reduce it, we measured this value using various kinds of pulleys for overhead contact line systems.

\subsection{Measurement method}

Figure 4 shows a schematic outline of the equipment used to measure resistance at supporting pulleys. PH356 wire was installed with two spans of $50 \mathrm{~m}$; a hydraulic actuator was installed at one termination, and a STB (with a standard tension of $19.6 \mathrm{kN}$ ) was fitted at the other. A pulley for measurement was installed at the central supporting point, and a load cell to measure the vertical load acting on the pulley was also attached. As mentioned above, supporting pulleys on messenger wires are structures that

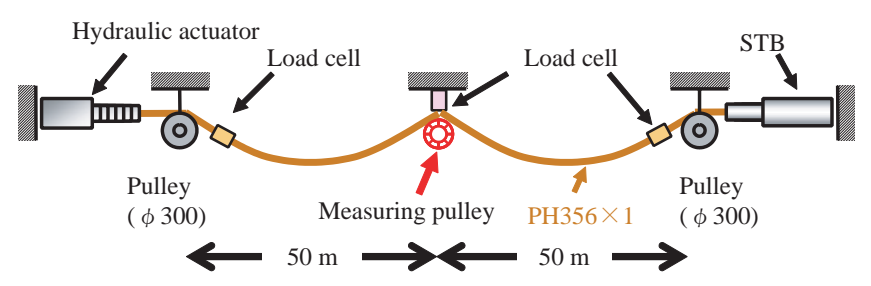

Fig. 4 Schematic outline of the equipment used to measure resistance at supporting pulleys

hold the wire up using two pulleys. In order to evaluate the characteristics of single pulleys, we measured not only the equipment of feeder messenger supporting pulleys as a whole but also a single pulley as an individual component of the equipment. A stainless steel cotter bolt was used as the axis for installation of a single pulley on a jig. The bolt had the same outer diameter and was made of the same material as the conventional axis.

When the actuator is pulled or pushed with constant speed, the tension of the messenger wire will fluctuate in the actuator-side span. If the tension difference between the actuator-side span and the STB-side span becomes larger than the resistance at the supporting pulley, the measuring pulley will rotate and the messenger wire will move. Since the tension difference is taken as the resistance at the supporting point, it is measured using the load cell installed into each span. This measurement is performed with the following operation: After pulling the actuator to its limit, operation is stopped for 15 seconds, then after pushing it to its limit, operation is stopped again for 15 seconds. This process is repeated five times. An outline of the measured results is shown in Fig. 5.

Since it is difficult to make the tension in both spans the same in the initial state of measurement, the average tension difference during pushing is subtracted from the corresponding value during pulling, and half of the result is taken as the control resistance value. In consideration of individual differences in manufactured pulleys, three measurements were made for supporting pulleys of each kind, and the measured values were averaged. Where the supporting pulley had insufficient width to support PH356, $3 \mathrm{~m}$ of trolley wire was installed with its center at the supporting point. Since the load applied to the pulley will change in this case, we evaluated the awkwardness of rotation using the rolling resistance coefficient.

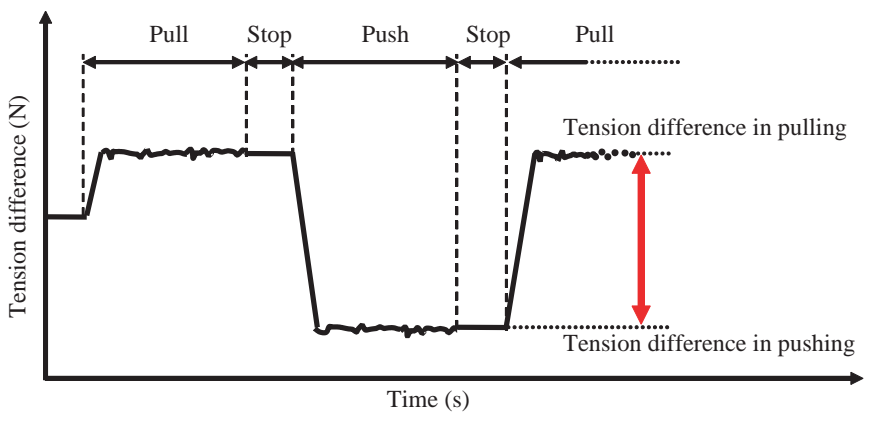

Fig. 5 Outline of the tension difference wave measured

\subsection{Measurement results}

Table 1 shows the results of measuring the rolling 
Table 1 Results of rolling resistance coefficient measurement

\begin{tabular}{|c|c|c|c|c|c|}
\hline No. & Measuring Pulley & The Material of Bush & $\begin{array}{c}\text { Bore / outer } \\
\text { diameter }\end{array}$ & $\begin{array}{c}\text { Rolling } \\
\text { resistance } \\
\text { coefficient }\end{array}$ & Remarks \\
\hline 1 & PH356 $\times 2$ for a straight & Molybdenum nylon & 0.50 & 0.085 & \\
\hline 2 & PH356 $\times 2$ for a curved & Molybdenum nylon & 0.30 & 0.061 & \\
\hline 3 & St90-135 × 1 & Nylon 6 & 0.35 & 0.057 & \\
\hline 4 & St90-135 $\times 1$ & Stainless steel & 0.35 & 0.117 & \\
\hline 5 & Pull-off pulley & Ball bearing & 0.17 & 0.003 & \\
\hline 6 & PH356 $\times 1$ for a straight & Molybdenum nylon & 0.30 & 0.058 & Single Pulley \\
\hline 7 & PH356 $\times 2$ for a curved & Molybdenum nylon & 0.30 & 0.138 & Single Pulley \\
\hline
\end{tabular}

resistance coefficient. The single pulley in the table corresponds to the case where just one pulley from the feeder messenger supporting equipment supports the messenger wire. The following points were confirmed from these results:

- In cases where the material of the pulley was the same, the smaller the ratio of bore/outer diameter (a/b in Fig. 2) is, the smaller the rolling resistance coefficient (No. 1 and No. 2 in Table 1) is

- Even if pulleys have the same form, the rolling resistance coefficient changes greatly depending on the kind of bush material used (No. 3 and No. 4 in Table 1).

- The pulley with a ball-bearing bush has an extremely small rolling resistance coefficient (No. 5 in Table 1).

- Since the equipment in No. 6 consists of two No. 1 pulleys, its rolling resistance coefficient is almost equivalent to that of No. 1. On the other hand, although the equipment in No.7 consists of two No. 2 pulleys, its rolling resistance coefficient is more than twice that of No. 2. To enable No. 7 to adapt itself to inclination from the lateral tension in a curve, an allowance is included between the pulley and its attachments. Hence, it can be presumed that the rolling resistance coefficient is greatly influenced by this allowance.

The above results indicate that lowering the bore/ outer diameter ratio, selecting a suitable material for the bush and decreasing the allowance between a pulley and its attachments are effective ways of reducing the rolling resistance coefficient of feeder messenger supporting pulleys.

\section{Field survey of tension on a commercial line}

In order to ascertain the tension distribution and horizontal movement of messenger wires on a commercial line, we performed measurement of these values in a feeder messenger system.

\subsection{Tension measurement method}

Although tension is generally measured using a load cell, this method is difficult on a commercial line, therefore, we used the oscillation method, in which accelerations of oscillation are measured when the overhead contact line is oscillated [1].

As shown in Fig. 6, when the overhead contact line is oscillated, acceleration at two measurement points separated by distance $L$ on the line is measured. Frequency $f_{n}$ for which the acceleration power spectral density of sum $A+$ and the difference $A-$ of the two measuring point is the minimum value and wave propagation velocity $c_{n}$ at frequency $f_{n}$ are calculated. Additionally, wave propagation velocity $c$ in consideration of rigidity and frequency is expressed as (5)

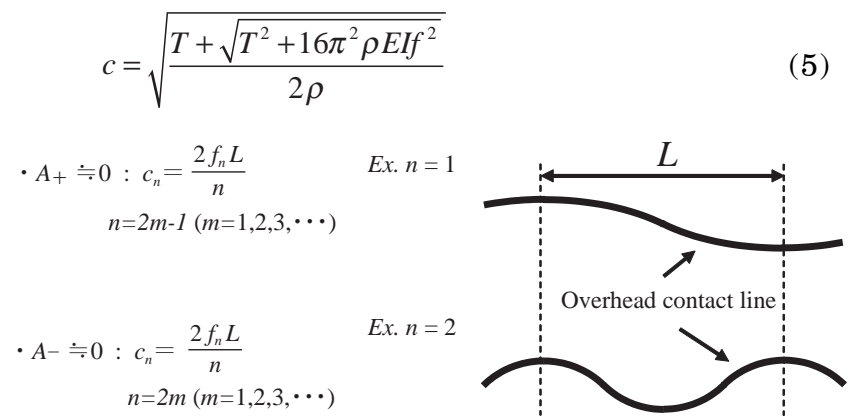

Fig. 6 Relationship between acceleration and wave propagation velocity

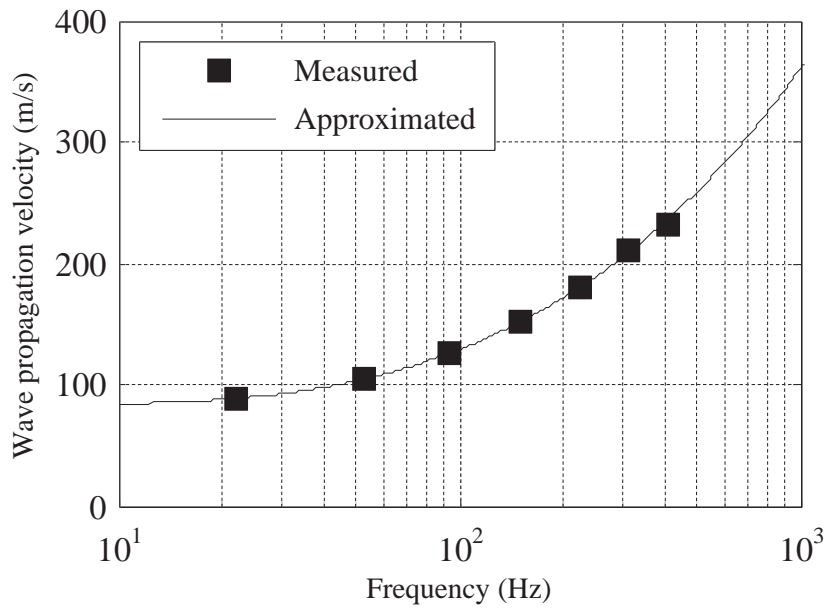

Fig. 7 Wave propagation velocity in an overhead contact line 
where $\rho=$ line density, $E I=$ flexural rigidity, $T=$ tension and $f=$ frequency.

As shown in Fig. 7, calculating the fitting curve of the relationship between measured frequencies $f_{n}$ and wave propagation velocity $c_{n}$ using (5) gives overhead contact line tension value $T$ [2].

\subsection{Results of tension measurement}

Tension measurement on an overhead contact line with a messenger wire supported by pulleys was performed five times over a period of a year. The number of measured drums was two; one included mainly curved sections (Drum 1), and the other included mainly straight sections (Drum 2). Figure 8 gives a schematic outline of the tension measurement setup, and shows the accelerometers installed in the messenger wire and contact wire between the hangers near the center between the supporting points. Tension was measured while a vibration exciter mounted on a road railer oscillated the contact wire.

The results of tension measurement are shown in Fig. 9. At the center of the Drums, the tension of the messenger wire changes sharply according to temperature changes. In the case of Drum 1, the tension changes from approximately $18 \mathrm{kN}$ at $25^{\circ} \mathrm{C}$ to $26 \mathrm{kN}$ at $7^{\circ} \mathrm{C}$, so the tension difference is approximately $8 \mathrm{kN}$ between summer and winter. On the other hand, the tension at points adjacent to both terminations is almost identical to that of the STB. On the contact wire, the tension is almost identical.

In order to verify the measured tension changing according to changes in temperature, the thermal tension fluctuation of the messenger wire in the span near the center of Drum 1 was calculated for a condition in which the messenger wire is fixed at both supporting points and the tension of the contact wire is constant. Figure 10 shows a comparison of the measurement results with

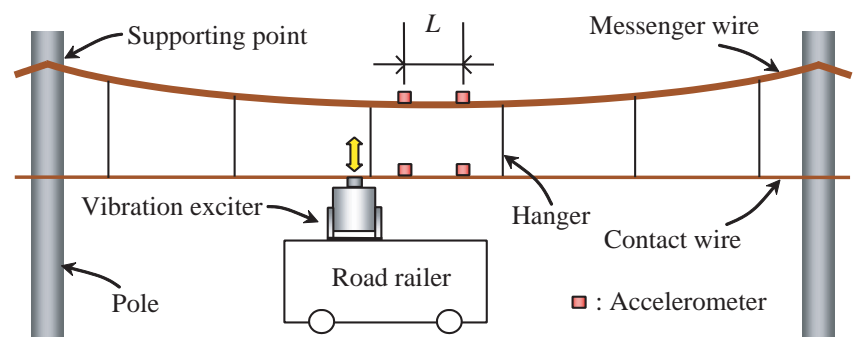

Fig. 8 Schematic outline of tension measurement

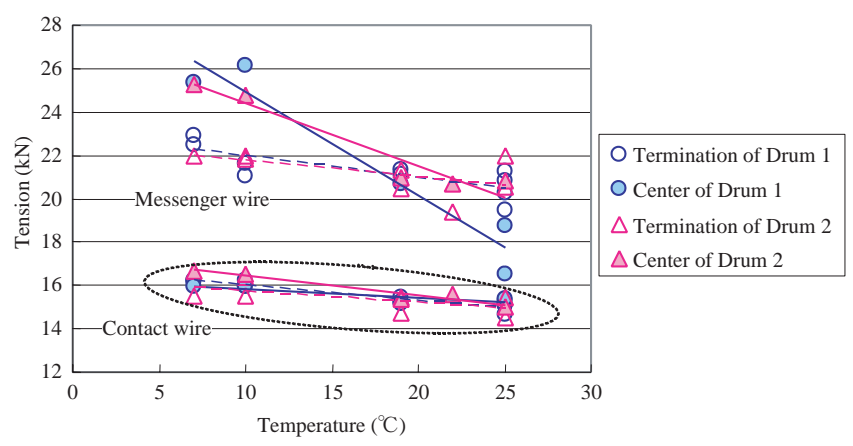

Fig. 9 Results of tension measurement

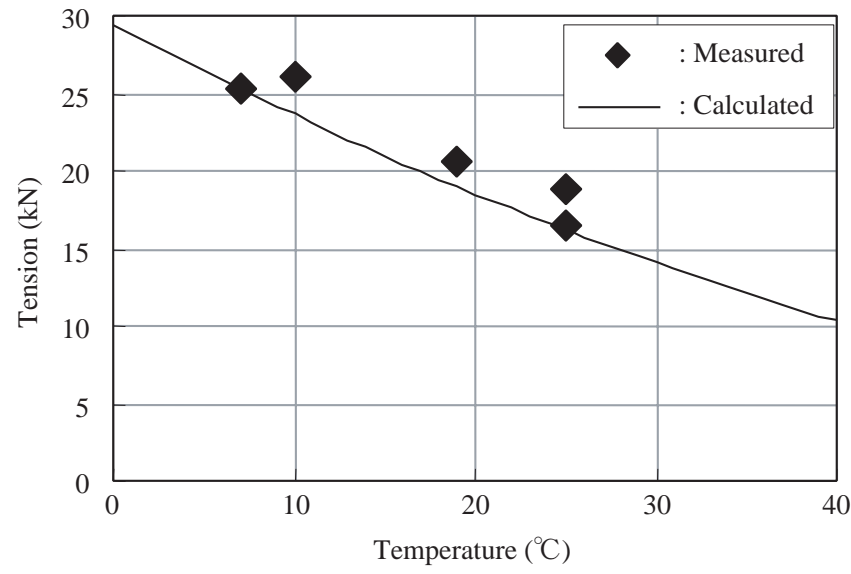

Fig. 10 Comparison of measurement results with calculated values

the calculated values, and indicates that they are almost identical. It can be assumed that the resistance at the pulley is so large that the messenger wires do not move smoothly, and that the tension of the messenger wire between the supporting points changes according to temperature change.

\subsection{Results of horizontal movement measurement}

Messenger wire horizontal movement was measured in the period from February to July, and the results were compared with the calculated values. Figure 11 shows the measurement results. The relative position in the drum normalized by the drum length is plotted on the $\mathrm{X}$-axis, and the relative positions of 0 and 1 indicate the values of the STB scale. Messenger wire adjacent to the termination moves smoothly, but that in the drum center does not move.

As seen from the measured values of Drum 1, the number of supporting points at which the messenger wire moved was approximately ten, counted from each termination. It can be presumed that tension values at points more than ten spans away from each termination are almost identical to those at the center of the drum. As seen from Fig. 9, the tension at the center of the drum changed

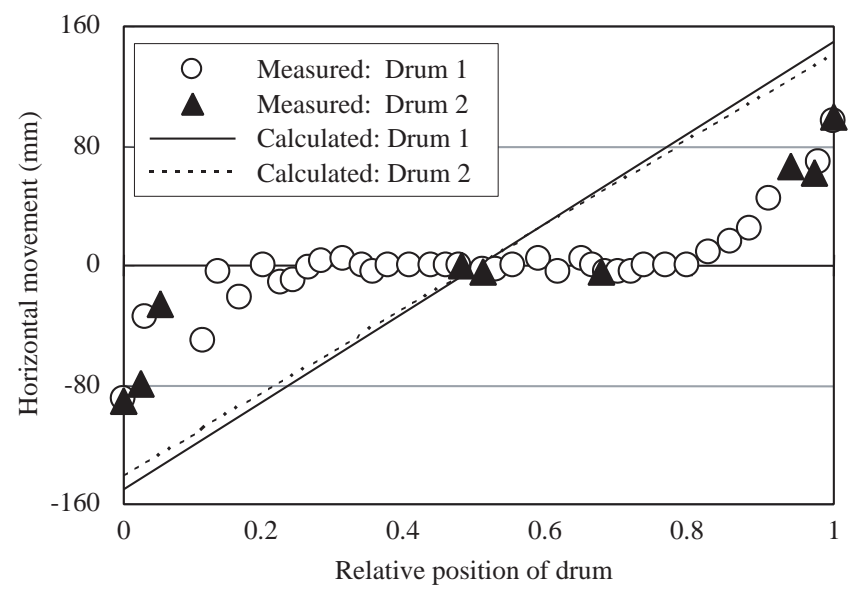

Fig. 11 Results of measuring messenger wire horizontal movement (February - June) 
by approximately $5 \mathrm{kN}$ from approximately $26 \mathrm{kN}$ in February $\left(7^{\circ} \mathrm{C}\right)$ up to approximately $21 \mathrm{kN}$ in June $\left(19^{\circ} \mathrm{C}\right)$, and the tension adjacent to the termination changed by approximately $1 \mathrm{kN}$ from approximately $22 \mathrm{kN}$ in February to approximately $21 \mathrm{kN}$ in June. It is assumed that this difference of $4 \mathrm{kN}(5 \mathrm{kN}-1 \mathrm{kN})$ contributed to the horizontal movement at the ten supporting points. The average tension per supporting point is $0.4 \mathrm{kN}$, which can be judged as the resistance at the supporting pulley that remained after pulley rotation.

\section{Effect of resistance at supporting pulleys on current collection performance}

It has been confirmed that tension fluctuation occurs in the area adjacent to the center of drums due to the resistance at supporting pulleys. If the tension is changed, the amount of dip also changed. It can be assumed that the resistance at the supporting pulley has a strong influence on current collection performance. Consequently, we conducted a simulation involving an overhead contact line and a pantograph to study the degree of influence.

\subsection{Simulation conditions}

In this simulation, the resistance at supporting pulley was set to such a large value that the messenger wires were fixed at all supporting points. The conditions of temperature were set at three levels: the a standard temperature of $15^{\circ} \mathrm{C}$, the minimum temperature of $-10^{\circ} \mathrm{C}$, and the a maximum temperature of $40^{\circ} \mathrm{C}$. The span lengths were $30 \mathrm{~m}, 40 \mathrm{~m}$ and $50 \mathrm{~m}$, and the number of spans was nine. As shown in Table 2, two kinds of pantograph mostly used in the metropolitan areas were selected. Although these have almost the same equivalent mass and spring constant, a major difference between them is the presence/absence of a pantograph damper $(80 \mathrm{Ns} / \mathrm{m}$ : singleaction damper). Since the pantograph spacing is different, calculation was made for both directions of movement. The running velocity was set from 70 to $140 \mathrm{~km} / \mathrm{h}$ at increments of $10 \mathrm{~km} / \mathrm{h}$.

\subsection{Simulation results}

Figure 12 shows the simulation results for contact force at $-10^{\circ} \mathrm{C}$ (the minimum temperature), $15^{\circ} \mathrm{C}$ (the standard temperature) and $40^{\circ} \mathrm{C}$ (the maximum temperature). When the tension in the contact wire increases at the minimum temperature, a hog state is achieved in which the wire becomes upward-convex, and when the tension decreases at the maximum temperature, a sag state occurs in which the wire becomes downward-convex. In cases with especially low tension, high contact forces were generated at the supporting points. Depending on the conditions, the contact force generated was nearly three times as large as that in a normal state; in this situation, it can be presumed that current collection performance deteriorates.

In order to investigate the extent of tension change to be allow to maintain current collection performance,
Table 2 Conditions of pantograph

\begin{tabular}{|l|l|l|}
\hline & \multicolumn{1}{|c|}{ Pantograph A } & \multicolumn{1}{c|}{ Pantograph B } \\
\hline Static upward force $(\mathrm{N})$ & 64 & 64 \\
\hline Equivalent mass $(\mathrm{kg})$ & $\mathrm{M}_{1}=13.1, \mathrm{M}_{2}=4.5, \mathrm{M}_{3}=8.3$ & $\mathrm{M}_{1}=14.8, \mathrm{M}_{2}=4.2, \mathrm{M}_{3}=8.7$ \\
\hline Spring constant $(\mathrm{N} / \mathrm{m})$ & $\mathrm{K}_{1}=10,720, \mathrm{~K}_{2}=21,520$ & $\mathrm{~K}_{1}=10,740, \mathrm{~K}_{2}=21,520$ \\
\hline Damping constant $(\mathrm{Ns} / \mathrm{m})$ & $\begin{array}{l}\mathrm{C}_{1}=50, \mathrm{C}_{2}=0, \mathrm{C}_{3}=80 \\
\text { (with single action damper) }\end{array}$ & $\mathrm{C}_{1}=0, \mathrm{C}_{2}=0, \mathrm{C}_{3}=0$ \\
\hline Spacing of pantograph $(\mathrm{m})$ & $80,120(3$ pantographs) & $40,40,40$ (4 pantographs) \\
\hline
\end{tabular}

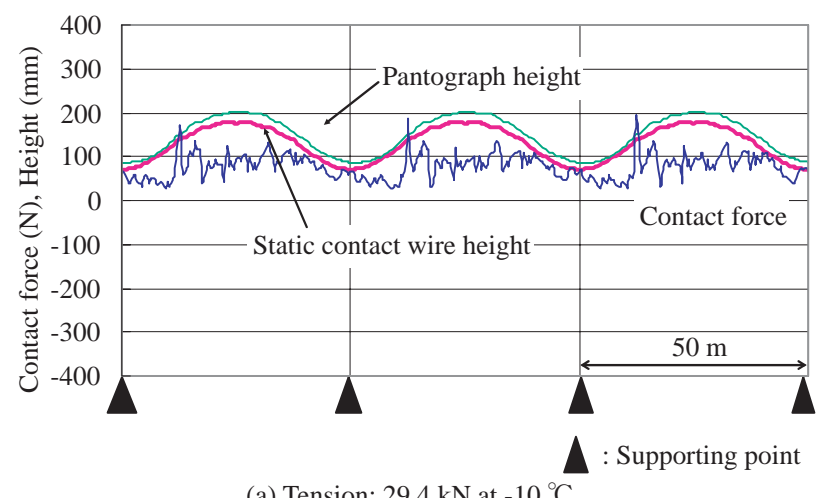

(a) Tension: $29.4 \mathrm{kN}$ at $-10{ }^{\circ} \mathrm{C}$

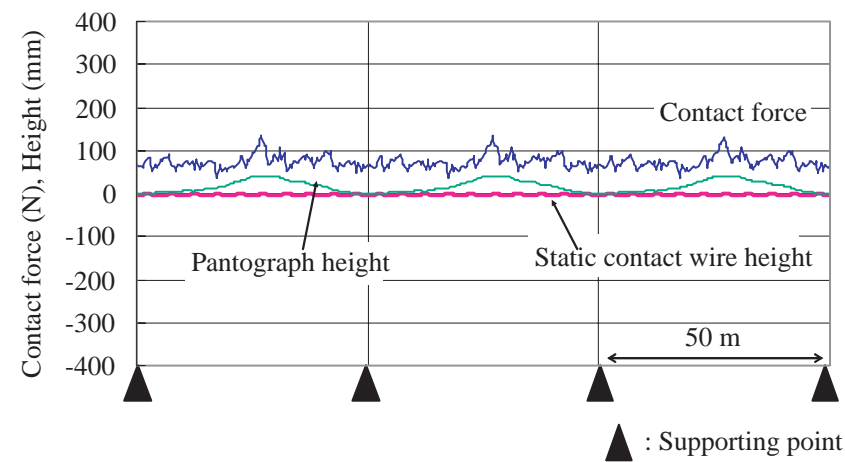

(b) Tension: $19.6 \mathrm{kN}$ at $-15{ }^{\circ} \mathrm{C}$

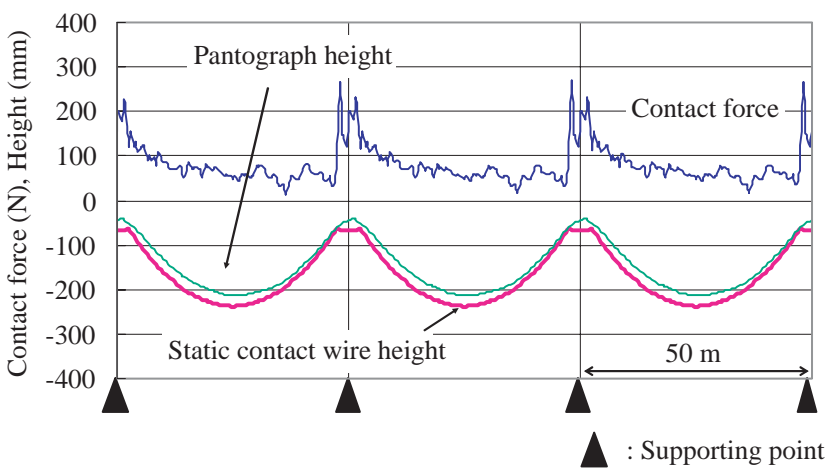

(c) Tension: $12.7 \mathrm{kN}$ at $-40{ }^{\circ} \mathrm{C}$

Fig. 12 Results of contact force simulation (Pantograph A, $110 \mathrm{~km} / \mathrm{h}$ )

we evaluated the contact loss ratio and the maximum contact loss time, which are indices indicating current collection performance. When either the contact loss ratio or the maximum contact loss time exceeds the criterion value ( $5 \%$ or $200 \mathrm{~ms}$ ), the allowable tension is judged to have been exceeded, and the tension levels just before the indices reach these thresholds are defined as the al- 


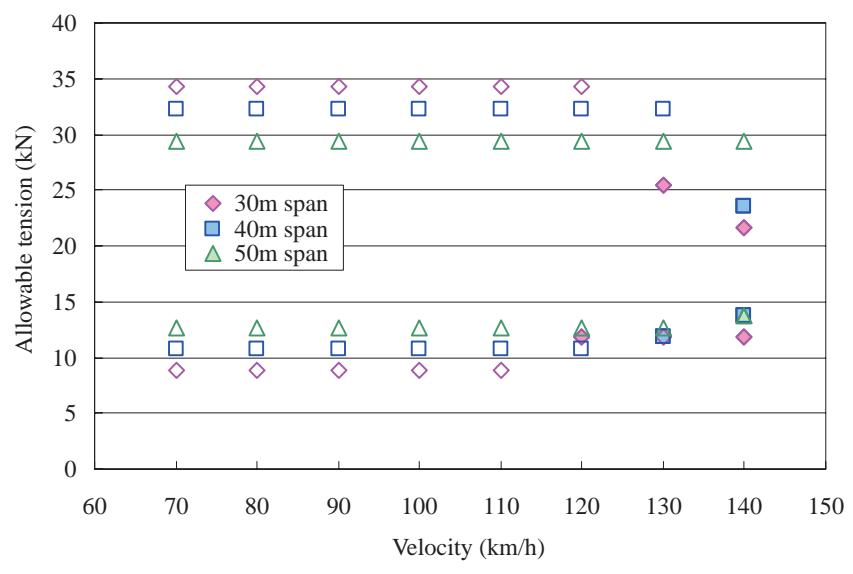

(a) Pantograph $\mathrm{A}$

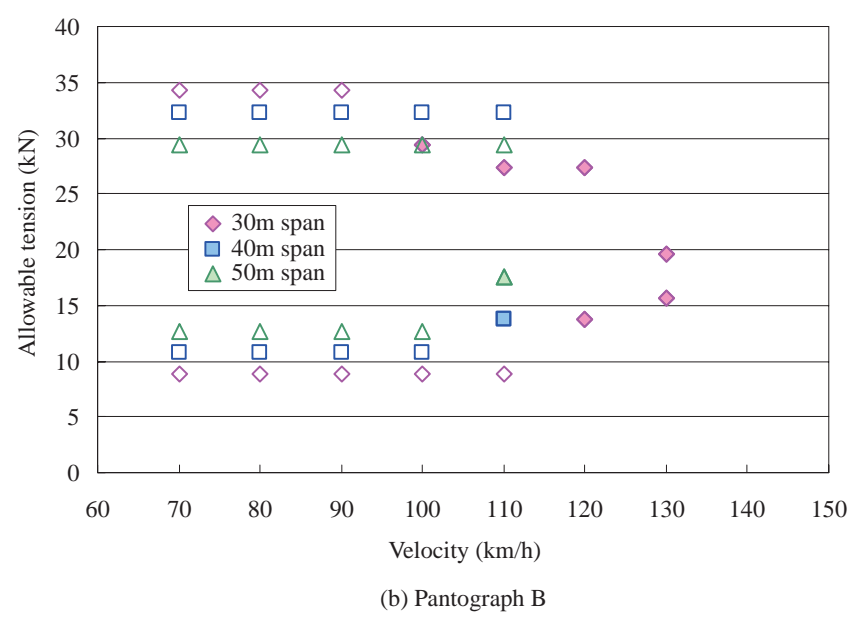

Fig. 13 Results of allowable tension simulation from the viewpoint of contact loss

lowable tension values. Figure 13 shows the simulation results of the allowable tension from the viewpoint of contact loss. However, the plot of the contour means that the thresholds for contact loss judgment are not exceeded even for tension at the assumed minimum and maximum temperatures. Hence, from the viewpoint of contact loss, even if the messenger wire is fixed at both supporting points, it is evident that there is no significant influence on current collection performance within the assumed temperature. The speed for which the index thresholds were not exceeded even at the assumed minimum and maximum temperatures was approximately $100 \mathrm{~km} / \mathrm{h}$ for Pantograph B (without a damper) and approximately $120 \mathrm{~km} / \mathrm{h}$ for Pantograph A (with a damper).

As mentioned previously, even if a large contact loss is not generated, a large contact force may be generated, which may cause local wear on the contact line. In order to stabilize current collection performance in further highspeed operation, reduction of resistance values at supporting pulleys is needed.

\section{Conclusions}

The authors investigated the mechanism of resistance at supporting pulleys as mentioned previously, and performed a simulation to study the effects of this resistance on current collection performance. The results can be summarized as follows:

- Resistance at supporting pulleys can be calculated as the tension difference between the spans on either side of a supporting pulley. There are two kinds of tension difference: one is the type required to rotate the pulley, and the other is the type that remains after the pulley stops rotating.

- Insulator inclination is caused by messenger wire movements in response to small temperature changes. If the temperature change is large, the pulley will rotate, and at the same time the inclined insulator will be returned almost to a neutral position.

- Both pulley rotation and insulator inclination therefore contribute significantly to messenger wire movement; if an insulator inclines, resistance at supporting pulleys become small because the force needed to restore the insulator will be added to the tension difference.

- Lowering the bore/outer diameter ratio, selecting a suitable material for the bush and decreasing the allowance between a pulley and its attachments are effective ways of reducing the rolling resistance coefficient of feeder messenger supporting pulleys.

- Since large tension fluctuation is generated and movement is not detected in the messenger wire of the span at drum centers, it can be presumed that messenger wire is in a state equivalent to being fixed at both supporting points.

- The speeds for which the threshold values for contact loss judgment are not exceeded, even if the messenger wire is fixed at both supporting points, was approximately $100 \mathrm{~km} / \mathrm{h}$ for a pantograph without a damper and approximately $120 \mathrm{~km} / \mathrm{h}$ for one with a damper.

\section{Acknowledgment}

The authors would like to express their sincere gratitude to the personnel involved at the East Japan Railway Company for their cooperation in this study.

\section{References}

[1] M. Aboshi and K. Manabe, "Wave Velocity Measurement of Contact Wire," The 74th JSME Fall Annual Meeting, Vol. IV , pp. 425-426, 1996.

[2] M. Aboshi, "Estimation method of contact wire tension by measuring unevenness," The 2002 National Conventional Record IEEJ, Vol. 5, pp. 2,132-2,133, 2001. 